\title{
KEJADIAN KELELAHAN KERJA SUBJEKTIF PADA PERAWAT DITINJAU DARI MASA KERJA
}

\author{
Rina Aprianti ${ }^{1}$, Susilo Wulan ${ }^{2}$, Elza Wulandari ${ }^{3}$ \\ Prodi Kesehatan Masyarakat, STIKES Tri Mandiri Sakti Bengkulu \\ rina.aprianti89@gmail.com ${ }^{1}$,wulan_susilo@yahoo.com ${ }^{2}$
}

\begin{abstract}
Fatigue is a feeling of tiredness, decreased alertness, decreased physical performance, decreased work motivation and in the end it can cause work accidents and reduce work productivity. The work period is the length of time a person works in a workplace and can have a negative effect, namely causing boredom and work fatigue.The purpose of this study was to determine the relationship between work tenure and subjective work fatigue in inpatient nurses at dr. M Yunus Bengkulu. This study was a type of analytic survey with a cross sectional approach which was carried out in $d r . M$ Yunus Bengkulu. The population is nurses. Sampling used a total sampling technique of 128 nurses. The independent variable in this study is tenure. The dependent variable in this study is subjective work fatigue. The instrument used was a questionnaire. The data analysis used is chi square, which is to test whether there is a relationship between independent and dependent variables.This study showed that most of the nurses experienced subjective work fatigue with the moderate category as many as 65 nurses (50.7\%) and had a service life of > 10 years as many as 84 (65.6\%). The results of the chi square test showed that there was a statistically significant relationship between years of service $(p=035)$. The conclusion of this study is that there is a statistically significant relationship between tenure and subjective work fatigue in inpatient nurses at RSUD Dr. M Yunus Bengkulu.
\end{abstract}

Keywords: Working Period, Subjective Work Fatigue

\begin{abstract}
ABSTRAK
Kelelahan kerja adalah perasaan lelah, penurunan tingkat kewaspadaan, penurunan kinerja fisik, penurunan motivasi kerja dan pada akhirnya dapat menyebabkan kecelakaan akibat kerja dan menurunkan produktivitas kerja. Masa kerja merupakan lamanya seseorang bekerja di suatu tempat kerja dan dapat memberikan pengaruh negatif yaitu menimbulkan kebosanan dan kelelahan kerja. Tujuan penelitian ini untuk mengetahui hubungan antara masa kerja dengan kelelahan kerja subjektif pada perawat rawat inap RSUD dr. M Yunus Bengkulu. Penelitian ini merupakan jenis survei analitik dengan pendekatan cross sectional yang dilaksanakan di RSUD dr. M Yunus Bengkulu dengan populasinya adalah perawat.. Pengambilan sampel menggunakan tehnik total sampling sebanyak 128 perawat. Variabel bebas dalam penelitian ini adalah masa kerja. Variabel terikat dalam penelitian ini adalah kelelahan kerja subjektif. Instrumen yang digunakan adalah kuesioner. Analisis data yang digunakan adalah chi square yaitu untuk menguji ada tidaknya hubungan antara variabel bebas dan terikat. Penelitian ini menunjukkan bahwa sebagian besar perawat mengalami kelelahan kerja subjektif dengan kategori sedang sebanyak 65 perawat (50,7\%) dan memiliki masa kerja > 10 tahun sebanyak $84(65,6 \%)$. Hasil uji chi square bahwa terdapat hubungan signifikan secara statistik antara masa kerja $(\mathrm{p}=0,035)$.Kesimpulan penelitian terdapat hubungan yang signifikan secara statistik antara masa kerja dengan kelelahan kerja subjektif pada perawat rawat inap RSUD dr M Yunus Bengkulu.
\end{abstract}

Kata Kunci: Masa Kerja, Kelelahan Kerja Subjektif. 


\section{PENDAHULUAN}

$\begin{array}{ccr}\text { Rumah } & \text { sakit adalah institusi } \\ \text { pelayanan } & \text { kesehatan } & \text { yang }\end{array}$ menyelenggarakan pelayanan kesehatan perorangan secara paripurna yang menyediakan pelayanan rawat inap, rawat jalan, dan gawat darurat (Permenkes RI No 30, 2019). Dimana tenaga kesehatan memiliki peranan yang cukup penting dalam menyelenggarakan pelayanan kesehatan di rumah sakit. Tenaga kesehatan adalah setiap orang yang mengabdikan dirinya dalam bidang kesehatan serta memiliki pengetahuan dan keterampilan melalui pendidikan di bidang kesehatan yang untuk jenis tertentu memerlukan kewenangan untuk melakukan upaya kesehatan (UU RI No 36 tahun 2014).

Perawat merupakan salah satu profesi di rumah sakit yang berperan penting dalam menyelenggarakan upaya menjaga mutu pelayanan kesehatan di rumah sakit. Pelayanan keperawatan merupaka suatu bentuk pelayanan profesional yang merupakan bagian integral dari pelayanan kesehatan yang didasarkan pada ilmu dan kiat keperawatan ditujukan kepada individu, keluarga, kelompok atau masyarakat, baik sehat maupun sakit (Permenkes RI No 26, 2019).

Menurut Word Health Organization (WHO) tahun 2013 tenaga kesehatan dunia berjumlah 43 juta, ini termasuk 9,8 juta dokter, 20,7 juta perawat/bidan, dan sekitar 13 juta kesehatan lainnya. Menurut Kemenkes RI, jumlah tenaga keperawatan yang ada di Indonesia tahun 2018 sebanyak 354.218, sehingga perawat merupakan tenaga kesehatan terbanyak (Kemenkes RI, 2018).

Perawat merupakan tenaga kesehatan terbanyak yang ada di rumah sakit terutama pada unit rawat inap yang memiliki jam kerja 24 jam dengan kondisi harus siap siaga untuk melayani pasien secara terus menerus. Kondisi pasien yang selalu bervariasi dan jumlah pasien yang selalu berubah membuat perawat sangat mudah mengalami kelelahan (Maharja, 2015).
Kelelahan (fatique) adalah suatu kondisi yang telah dikenal dalam kehidupan sehari-hari. Istilah kelelahan mengarah pada kondisi melemahnya tenaga untuk melakukan suatu kegiatan, walaupun itu bukan satu-satunya gejala. (Budiono, et al, 2003).

Kelelahan kerja yang dialami oleh perawat di bangsal rawat inap RS Islam Fatimah Cilacap tergolong dalam tingkat kelelahan kerja yang tinggi yaitu 63,8\% (Kurniawati et al, 2012). Selain itu penelitian Astuti et al, pada perawat di rumah sakit menunjukkan $70,7 \%$ perawat yang mengalami kelelahan kerja berat dan sedang (Astuti et al, 2017).

Perasaan kelelahan kerja cenderung meningkatkan terjadinya kecelakaan kerja, sehingga dapat merugikan diri pekerja sendiri maupun perusahaannya karena adanya penurunan produktivitas kerja. Kelelahan kerja terbukti memberikan kontribusi lebih dari $60 \%$ dalam kejadian kecelakaan kerja di tempat kerja (Setyawati, 2010).

Kelelahan kerja disebabkan oleh banyak faktor yang dapat berasal dari internal pekerja seperti usia, jenis kelamin, jumlah tanggungan keluarga, status gizi, tingkat pendidikan, waktu dan lamanya kerja di tempat tersebut maupun dari faktor eksternal yang berasal dari lingkungan kerja (Setyawati, 2010). Masa kerja dapat memberikan pengaruh positif maupun negatif. Menurut Astuti et al, ada hubungan antara masa kerja dengan kelelahan kerja pada perawat (Astuti et al, 2017).

Rumah sakit dr. M. Yunus Bengkulu merupakan rumah sakit umum daerah milik pemerintah provinsi dan juga sebagai rumah sakit rujukan untuk wilayah Bengkulu dengan jumlah pasien yang sangat banyak. Jumlah perawat diruag rawat inap sekitar 128 orang. Hasil observasi yang dilihat dari jumlah perawat yang ada di ruang rawat inap dengan jumlah pasien tidak seimbang. Hal ini karena jumlah pasien yang banyak serta selalu berganti dengan berbagai penyakit yang diderita. Berdasarkan latar belakang 
tersebut maka peneliti tertarik untuk melakukan penelitian ini. Tujuan dari penelitian ini untuk mengetahui hubungan antara masa kerja dengan kelelahan kerja subjektif pada perawat rawat inap RSUD dr. M Yunus Bengkulu.

\section{METODE}

Penelitian ini adalah jenis penelitian survei analitik dengan pendekatan cross sectional. Variabel independen adalah masa kerja dan variabel dependen adalah kelelahan kerja subjektif. Populasi dalam penelitian ini adalah seluruh perawat yang ada di ruang rawat inap RSUD dr. $M$. Yunus Bengkulu yaitu 128 perawat. Sampel penelitian ini adalah 128 perawat dengan teknik pengamilan sampel yaitu total sampling. Lokasi penelitian ini di RSUD dr. M Yunus Bengkulu yang dilaksanakan pada bulan Agustus 2020. Penelitian ini menggunakan data primer dengan instrumen penelitian yaitu kuesioner, dan data sekunder untuk melihat jumlah perawat yang ada di ruang rawat inap RSUD dr. M. Yunus Bengkulu. Analisis data adalah analisis univariat untuk mengetahui distribusi dan frekuensi dari variabel independen dan analisis bivariat untuk mengetahui hubungan antara variabel independen dan variabel dependen. Dengan menggunakan uji chi square dengan derajat kesalahan $95 \%$ jika p value $\leq 0,05$ menunjukkan hubungan bermakna dan jika > 0,05 tidak bermakna.

\section{HASIL}

Tabel 1. Distribusi Frekuensi Variabel Penelitian

\begin{tabular}{lcc}
\hline \multicolumn{1}{c}{ Variabel } & Frekuensi & \% \\
\hline Kelelahan Kerja & & \\
Subjektif & & \\
$\quad$ Sedang & 65 & 50,7 \\
$\quad$ Berat & 63 & 49,2 \\
\hline Masa Kerja & & \\
$\quad$ 10 Tahun & 44 & 34,4 \\
$\quad$ 10 Tahun & 84 & 65,6 \\
\hline
\end{tabular}

Tabel 1. Menunjukkan bahwa dari 128 perawat yang mengalami kelelahan kerja subjektif dengan kategori sedang sebanyak 65 perawat $(50,7 \%)$ dan kategori berat sebanyak 63 perawat $(49,2 \%)$. Perawat dengan masa kerja $\leq 10$ Tahun sebanyak 44 perawat $(34,4 \%)$ dan masa kerja $>10$ tahun sebanyak $84(65,6 \%)$.

Tabel 2. Hubungan Masa Kerja dengan Kelelahan Kerja Subjektif pada Perawat

\begin{tabular}{|c|c|c|c|c|c|c|c|}
\hline \multirow[t]{3}{*}{ Masa Kerja } & \multicolumn{4}{|c|}{ Kelelahan Kerja Subjektif } & \multirow[t]{3}{*}{ Jumlah } & \multirow[t]{3}{*}{ Presentase } & \multirow[t]{3}{*}{ p value } \\
\hline & \multicolumn{2}{|c|}{ Sedang } & \multicolumn{2}{|c|}{ Berat } & & & \\
\hline & $\mathbf{f}$ & $\%$ & f & $\%$ & & & \\
\hline$\leq 10$ Tahun & 28 & 63,6 & 16 & 36,4 & 44 & 100 & 0,035 \\
\hline$>10$ Tahun & 37 & 44,1 & 47 & 55,9 & 84 & 100 & \\
\hline Jumlah & 65 & 50,8 & 63 & 49,2 & 128 & 100 & \\
\hline
\end{tabular}

Tabel 2. menunjukkan bahwa dari 44 perawat yang masa kerjanya $\leq 10$ tahun terdapat $28((63,6 \%)$ perawat mengalami kelelahan kerja subjektif sedang dan 16 $((36,4 \%)$ perawat yang mengalami kelelahan kerja sujektif berat. Sedangkan 84 perawat yang masa kerjanya $>10$ tahun terdapat $37(44,1 \%)$ perawat mengalami kelelahan kerja subjektif sedang dan 63 $((49,2 \%)$ perawat yang mengalami kelelahan kerja sujektif berat.
Berdasarkan hasil chi square diperoleh nilai $\mathrm{p}$ value sebesar $0,035(\mathrm{p}<0,05)$. Hal ini menunjukkan bahwa terdapat hubungan yang signifikan secara statistik antara masa kerja dengan kelelahan kerja subjektif pada perawat rawat inap RSUD dr M Yunus Bengkulu.

\section{PEMBAHASAN}

Berdasarkan hasil penelitian diperoleh hasil bahwa perawat dengan 
masa kerja $\leq 10$ tahun terdapat $28((63,6 \%)$ perawat mengalami kelelahan kerja subjektif sedang dan $16((36,4 \%)$ perawat yang mengalami kelelahan kerja sujektif berat. Hal ini karena, perawat mendapatkan shift kerja malam hari yang mempunyai durasi kerja lebih lama sehingga perawat mengalami kelelahan berat.

Sedangkan 84 perawat yang masa kerjanya $>10$ tahun terdapat $63((49,2 \%)$ perawat yang mengalami kelelahan kerja sujektif berat, karena perawat dengan masa kerja ini memiliki umur > 35 tahun dan 37 $(44,1 \%)$ perawat mengalami kelelahan kerja subjektif sedang. Hal ini karena, perawat mempunyai komunikasi yang baik dengan sesama rekan kerja sehingga dalam melakukan pekerjaan menjadi lebih mudah. Pengalaman kerja yang lama membuat perawat senior lebih mudah dalam mengatur kondisi ketahanan mental maupun fisik dalam melaksanakan pekerjaannya.

Berdasarkan hasil chi square menunjukkan bahwa terdapat hubungan yang signifikan secara statistik antara masa kerja dengan kelelahan kerja subjektif pada perawat rawat inap RSUD dr M Yunus Bengkulu.

Penelitian ini sejalan dengan penelitian yang dilakukan oleh Dewi et al, bahwa terdapat hubungan yang bermakna antara masa kerja dengan kelelahan kerja pada perawat (Dewi et al, 2016). Menurut penelitian Indah (2011) ada hubungan antara masa kerja dengan perasaan kelelahan kerja.

Masa kerja adalah pengetahuan atau keterampilan yang telah diketahui dan dikuasai seseorang yang akibat dari perbuatan atau pekerjaan yang telah dilakukan selama beberapa waktu tertentu. Masa kerja juga dapat diartikan suatu ukuran lama waktu seseorang dalam bekerja, yang dapat meningkatkan pengetahuan serta keterampilan seseorang dalam pekerjaanya. Masa kerja dapat memberikan pengaruh positif maupun negatif. Pengaruh positif muncul dikarenakan dengan bertambahnya masa kerja maka pengalaman dalam melaksanakan tugasnya akan bertambah. Sebaliknya dapat memberikan pengaruh negatif jika semakin bertambahnya masa kerja maka akan muncul kebiasaan pada pekerja (Suma'mur, 2014).

\section{KESIMPULAN}

Berdasarkan hasil penelitian maka dari 128 perawat yang mengalami kelelahan kerja subjektif dengan kategori sedang sebanyak 65 perawat $(50,7 \%)$. Perawat dengan masa kerja > 10 tahun sebanyak 84 $(65,6 \%)$. Kesimpulan bahwa terdapat hubungan yang signifikan secara statistik antara masa kerja dengan kelelahan kerja subjektif pada perawat rawat inap RSUD dr $\mathrm{M}$ Yunus Bengkulu dengan nilai $\mathrm{p}$ value sebesar 0,035 ( $\mathrm{p}<0,05)$. Kepada pihak RSUD dr M Yunus Bengkulu agar dapat melakukan upaya penanggulangan kelelahan kerja pada tenaga kesehatan terutaman perawat, melalui upaya penyuluhan tentang kelelahan. Kepada peneliti agar dapat mengembangkan penelitian ini dengan variabel lainnya yang berhubungan dengan kelelahan kerja subjektif pada perawat.

\section{UCAPAN TERIMAKASIH}

Ucapan terimaksih disampaikan kepada Direktorat Riset dan Pengabdian Masyarakat, Direktorat Jenderal Penguatan Riset dan Pengembangan, Kementerian Riset, Teknologi / Badan Riset dan Inovasi Nasional.

\section{DAFTAR PUSTAKA}

Astuti, F. W., Ekawati, E., \& Wahyuni, I. (2017). Hubungan Antara Faktor Individu, Beban Kerja dan Shift Kerja dengan Kelelahan Kerja pada Perawat di RSJD Dr. Amino Gondohutomo Semarang. Jurnal Kesehatan Masyarakat (eJournal), 5(5).pp. 163-172. 
Budiono, A.M.S., Jusuf, R.M.S. \& Pusparini, A. (2003) Bunga Rampai Hiperkes dan KK. Semarang: Badan Penerbit UNDIP.

Dewi, A. C., Agus, S., \& Adi, H. S. (2016). Stres Kerja, Usia, dan Lama Layanan dengan Kelelahan Kerja pada Perawat Di Rumah Sakit Jiwa Grhasia Yogyakarta. BKM Journal of Community Medicine and Public Health, 32(2). pp. 53-58.

Indah, M.F. (2011). Hubungan Faktor Individu dengan Perasaan Kelelahan Kerja dan Waktu Reaksi Pengemudi Moil Tangki di PT X Tahun 2011. Tesis, Universitas Gadjah Mada

(Kesehatan, 2014)

Kemenkes RI, 2018. Data dan Informasi Profil Kesehatan Indonesia Tahun 2018

Kurniawati, D., \& Solikhah, S. (2012). Hubungan Kelelahan Kerja Dengan Kinerja Perawat Di Bangsal Rawat Inap Rumah Sakit Islam Fatimah Kabupaten Cilacap. Kes Mas: Jurnal Fakultas Kesehatan Masyarakat Universitas Ahmad Daulan, 6(2).pp. 162-232.

Maharja R. (2015) Analisis Tingkat Kelelahan Kerja Berdasarkan Beban Kerja Fisik Perawat Di Instalasi Rawat Inap RSU Haji Surabaya.
The indonesian jurnal of occupational safety and health,4(1). pp. 93-102.

Permenkes RI (2019) Nomor 26. Peraturan Pelaksanaan UU No 38 Tahun 2014 tentang Keperawatan. Tahun 2019

Permenkes RI (2019) Nomor 30. Tentang Klasifikasi dan Perizinan Rumah Sakit.

Setyawati, L. (2010). Sekilas Tentang Kelelahan Kerja. Penerbit Amara Books: Yogyakarta

Undang-Undang Republik Indonesia Nomor 36 Tahun 2014 Tenaga Kesehatan. 